\title{
Delftia lacustris sp. nov., a peptidoglycan- degrading bacterium from fresh water, and emended description of Delftia tsuruhatensis as a peptidoglycan-degrading bacterium
}

Correspondence

Niels O. G. Jørgensen

nogj@life.ku.dk

\author{
Niels O. G. Jørgensen, ${ }^{1}$ Kristian K. Brandt, ${ }^{1}$ Ole Nybroe ${ }^{1}$ \\ and Michael Hansen ${ }^{2}$ \\ ${ }^{1}$ Department of Agriculture and Ecology, Faculty of Life Sciences, University of Copenhagen, \\ Thorvaldsensvej 40, DK 1871 Frederiksberg, Denmark \\ ${ }^{2}$ Department of Plant Biology and Biotechnology, Faculty of Life Sciences, University of \\ Copenhagen, Thorvaldsensvej 40, DK 1871 Frederiksberg, Denmark
}

\begin{abstract}
Extracellular peptidoglycan is commonly found in natural environments, yet little is known about its biodegradation in nature. We here describe a novel peptidoglycan-degrading bacterium, designated strain $332^{\top}$, isolated from mesotrophic lake water in Denmark. The strain was a Gramnegative-staining, motile rod. It had chitinase and lysozyme activities, which are relevant to peptidoglycan degradation, and was capable of utilizing several mono- and disaccharides, amino acids and organic acids. Phylogenetic analysis based on the 16S rRNA gene sequence indicated that strain $332^{\top}$ belonged to the genus Delftia. Fatty acids of the strain included $\mathrm{C}_{8: 0}$ and $\mathrm{C}_{10: 0}$, which are characteristic of the genus Delftia. The DNA G+C content of the strain was $65.3 \mathrm{~mol} \%$. A DNA-DNA hybridization value of $66.2 \%$ was found between strain $332^{\top}$ and Delftia tsuruhatensis DSM $17581^{\top}$. Based on differences in physiological and biochemical characteristics, the strain is considered to represent a novel species, for which the name Delftia lacustris sp. nov. is proposed. The type strain is $332^{\top}\left(=\mathrm{DSM} 21246^{\top}=\mathrm{LMG} 24775^{\top}\right)$. An emended description of Delftia tsuruhatensis is also presented.
\end{abstract}

Extracellular peptidoglycan (PG) components commonly occur in nature (Benner \& Kaiser, 2003). These cell-wall compounds have been found to be degradable by indigenous bacteria, but at a lower rate than other polymers of bacterial origin, such as proteins (Nagata et al., 2003). During growth, large portions of PG in Gramnegative bacteria are recycled by being degraded and reassimilated (Park \& Uehara, 2008), but it is not known whether the enzymes involved in this recycling are also engaged in utilization of extracellular PG. Degradation of PG and chitin may involve related enzymic processes, because the glycan backbones of PG and chitin possess similar $\beta(1,4)$ bonds, and some bacterial chitinases also have lysozyme activity (Wang \& Chang, 1997). To our knowledge, bacterial species that are capable of degrading extracellular PG have not previously been described. We report here the characterization of a novel strain that degrades extracellular PG. The strain, designated strain

\footnotetext{
Abbreviations: MUF, methyl umbelliferyl; PG, peptidoglycan; SEM, scanning electron microscopy.

The GenBank/EMBL/DDBJ accession number for the 16S rRNA gene sequence of strain $332^{\top}$ is EU888308.
}

$332^{\mathrm{T}}$, was isolated from mesotrophic lake water and cultivated on PG-enriched media [tryptic soy agar (TSA) or dilute tryptic soy broth (TSB) (0370-17-1; Difco) amended with $2 \mathrm{mg} \mathrm{PG}^{-1}$ ]. Analysis of its $16 \mathrm{~S}$ rRNA gene sequence revealed that strain $332^{\mathrm{T}}$ clustered within the genus Delftia. The genus Delftia includes two recognized species, Delftia acidovorans (isolated from soil) and Delftia tsuruhatensis (isolated from sludge) (Wen et al., 1999; Shigematsu et al., 2003). On the basis of phenotypic and molecular analysis, we propose that strain $332^{\mathrm{T}}$ represents a novel species within the genus Delftia.

Lake-water microcosms were established with filtered water $(0.8 \mu \mathrm{m}$ pore size) collected from the mesotrophic Lake Sjælsø, northern Zealand, Denmark. The microcosms were supplemented with PG from Bacillus sp. strain A6 (Frette et al., 2004). PG was purified according to the method of Pelz et al. (1998) (see details below) and added to a final concentration of $2 \mathrm{mg} \mathrm{l}^{-1}$. After incubation for 7 days at $20{ }^{\circ} \mathrm{C}$, bacteria from the microcosms were cultivated on $1 /$ 10 LB agar (Eisenstadt et al., 1994). Subsequently, isolates were transferred to 1/10 LB agar supplemented with PG (or with heat-denatured cell-wall material) from Bacillus sp. strain A6 and isolates that formed clearing zones were 
selected for further analysis. Strain $332^{\mathrm{T}}$ was selected because of its capacity to form distinct but opaque clearing zones. The strain was routinely cultured in LB broth or TSB in shake flasks incubated overnight at $22{ }^{\circ} \mathrm{C}$.

Standard physiological analyses were performed on cells grown at $22{ }^{\circ} \mathrm{C}$ in TSB or on $1 / 10$ TSA at $\mathrm{pH} 7.2$, using individual tests and multi-substrate kits. Tests for strain $332^{\mathrm{T}}, D$. tsuruhatensis DSM $17581^{\mathrm{T}}$ and D. acidovorans DSM $39^{\mathrm{T}}$ were performed under identical conditions with parallel cultures. The individual tests included the Gram designation ( $\mathrm{KOH}$ method), oxidase activity (BBL Dryslide Oxidase kit; $\mathrm{BD})$, catalase activity $\left(\mathrm{H}_{2} \mathrm{O}_{2}\right.$ addition), oxidation or fermentation of glucose (test according to Hugh \& Leifson, 1953), casein hydrolysis (detection of clearing zones on LB agar enriched with $3 \%$ skimmed milk), lysozyme activity (EnzChek lysozyme assay kit; Invitrogen), DNase activity [detection of clearing zones in

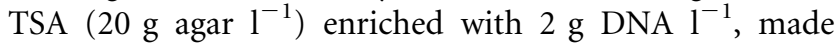
visible after addition of $1 \mathrm{M} \mathrm{HCl}$ (Jeffries et al., 1957)] and chitinase, cellulose and starch degradation using the methyl umbelliferyl (MUF) substrate analogues MUF $N$-acetyl- $\beta$ glucosaminide, MUF $\beta$-glucosidase and MUF $\alpha$-glucosidase (Sigma-Aldrich). The MUF substrates were applied as described elsewhere (O’Brien \& Colwell, 1987; Cody, 1989). Briefly, $30 \mu \mathrm{l}$ MUF substrate was added to $4 \mathrm{~cm}$ filter-paper discs, after which material from several colonies was rubbed onto the surface of the discs. The discs were incubated at $28{ }^{\circ} \mathrm{C}$ for $30 \mathrm{~min}$ and then $50 \mu \mathrm{l}$ saturated sodium bicarbonate solution was added to each disc. The discs were exposed to UV light and appearance of blue fluorescence indicated a positive reaction.

Because of the close phylogenetic relationship between strain $332^{\mathrm{T}}$ and D. tsuruhatensis relative to D. acidovorans, most tests were only performed on strain $332^{\mathrm{T}}$ and $D$. tsuruhatensis DSM $17581^{\mathrm{T}}$. The multi-substrate kits that were used were API 20NE, API $50 \mathrm{CH}$ (carbohydrate utilization) and API ZYM (various enzymes) (bioMérieux) and GN2 MicroPlate and EcoPlate (Biolog), according to the manufacturers' instructions. For analysis of whole-cell fatty acids and DNA-DNA hybridization, cells of $D$. tsuruhatensis DSM $17581^{\mathrm{T}}$, D. acidovorans DSM $39^{\mathrm{T}}$ (DNA-DNA hybridization only) and strain $332^{\mathrm{T}}$ were grown in TSB under identical growth conditions. Genomic $\mathrm{G}+\mathrm{C}$ content and whole-cell fatty acids were analysed by HPLC analysis and GC-MS, respectively, at the DSMZ. DNA-DNA hybridization was performed in duplicate according to De Ley et al. (1970) at the DSMZ.

Degradation of extracellular PG was tested with liquid and solid media, each with a different method of quantification. PG from Erythrobacter sp. (class Alphaproteobacteria) was purified according to Pelz et al. (1998). Briefly, the extraction included SDS treatment at $100{ }^{\circ} \mathrm{C}$ for $1 \mathrm{~h}$ to obtain cell lysis, sonication for $1 \mathrm{~min}$ for further cell destruction, digestion with trypsin to remove proteins and extraction of lipids with organic solvents of decreasing polarity. The purified PG was added to $1 / 25$ TSB and 1/25
TSA that was poured on top of $1 / 25$ TSA without PG. The final PG concentration was $2 \mathrm{mg} \mathrm{l}^{-1}$ in both the liquid medium and the top layer. In the $1 / 25 \mathrm{TSB}$, growth of inoculated cells was measured as the increase in cell density relative to controls (1/25 TSB without PG). At daily intervals, $50 \mu \mathrm{l}$ of a $1: 10000$-diluted stock solution of SYBR Green I stain (Invitrogen) was added to triplicate subsamples of $2 \mathrm{ml}$, after which the fluorescence intensity (excitation $490 \mathrm{~nm}$; emission $520 \mathrm{~nm}$ ) was determined. For tests on solid medium, cells were spread on 1/25 TSA plates with and without a PG-containing top layer. Utilization (hydrolysis) of PG was determined from clearing (opaque) zones around the colonies formed on the almost-transparent PG-containing agar.

Capacity for growth was tested at different temperatures (3, $5,10,20,25,30$ and $\left.37{ }^{\circ} \mathrm{C}\right)$, salinities $(0,1,3,6$ and $10 \%$, $\mathrm{w} / \mathrm{v}, \mathrm{NaCl})$ and $\mathrm{pH}(\mathrm{pH} \mathrm{5}, 6,7,8,9$ and 10) in $10 \mathrm{ml}$ of $1 / 10$ or full-strength TSB incubated on a shaking table at $20{ }^{\circ} \mathrm{C}\left(3-37^{\circ} \mathrm{C}\right.$ for analysis of temperature preference). Similarly, the growth rate was determined at $20{ }^{\circ} \mathrm{C}$ in both $1 / 10$ and full-strength TSB.

Cellular morphology and size of strain $332^{\mathrm{T}}$ were determined by scanning electron microscopy (SEM) of an overnight culture grown in $1 / 10$ TSB and filtered onto $0.2 \mu \mathrm{m}$ pore-size polycarbonate filters. The filters were fixed and dehydrated according to Watson et al. (1980), mounted on aluminium stubs and sputter-coated with gold/palladium. The cells were observed with a Quanta 200 SEM microscope (FEI Company). Sizes of the cells were measured using the program LCS LITE (Leica Microsystems).

Genomic DNA was isolated from strain $332^{\mathrm{T}}$ after cultivation of cells in TSB overnight as described previously (Brandt et al., 2006). The 16S rRNA gene sequence was amplified by PCR using primers Fd1 and Rd1 (Brandt et al., 1999) and purified by a QIAquick PCR purification kit (Qiagen). The nearly complete $16 \mathrm{~S}$ rRNA gene sequence (1543 bp) was obtained by sequencing the gene in both directions (GATC Biotech).

Strain $332^{\mathrm{T}}$ was a Gram-negative-staining, non-sporeforming, motile (although no flagella were observed by SEM) rod-shaped bacterium. Cells were $2.3 \pm 0.7 \mu \mathrm{m}$ long and $0.7 \pm 0.1 \mu \mathrm{m}$ wide. Cells grew between 3 and $37^{\circ} \mathrm{C}$, with optimum growth at $25{ }^{\circ} \mathrm{C}$. Growth was observed at $\mathrm{pH} 5-10$, with optimum growth at $\mathrm{pH} 6-7$. Growth was observed at salinities from 0 to $6 \mathrm{~g} \mathrm{NaCl}^{-1}$, with optimum growth at $1 \mathrm{~g} \mathrm{l}^{-1}$. The cells were oxidase- and catalase-positive. Growth occurred on the following compounds with oxygen as the electron acceptor: phenylacetic acid, L-asparagine, adipic acid, 4-hydroxybenzoic acid, $\alpha$-ketobutyric acid, caproic acid, citrate, gluconic acid, 2- and 5-ketogluconate, itaconic acid, D-malic acid, malonic acid, L-phenylalanine, L-threonine, L-arabinose, $\mathrm{N}$-acetyl-D-glucosamine (weak reaction), D-mannose, glycogen, D-mannitol, gelatin, pyruvic acid methyl ester and Tweens 40 and 80 . Nitrate reduction to nitrite occurred, but no anaerobic growth or fermentation was observed, as 
determined from the O-F reaction (Hugh \& Leifson, 1953). Doubling times at $20{ }^{\circ} \mathrm{C}$ were 6.0 and $1.7 \mathrm{~h}$ in $1 / 10$ and full-strength TSB, respectively. The following compounds did not support growth: D-glucose, cellobiose, aesculin, galactopyranoside, glucose 1-phosphate, glycogen, maltose, $\alpha$-cyclodextrin, methyl $\beta$-D-glucoside, D-xylose, i-erythritol, $\mathrm{D}$-galactonic acid $\gamma$-lactone, L-arginine, D-galacturonic acid, 2-hydroxybenzoic acid, L-serine, D-glucosaminic acid, glycyl L-glutamic acid, phenylethylamine, $\alpha$-lactose, DL- $\alpha$ glycerol phosphate, putrescine and tryptophan. Enzyme activities of strain $332^{\mathrm{T}}$ included acid and alkaline phosphatases, chitinase, esterase (C4), esterase lipase (C8), $\alpha$ - and $\beta$-glucosidases, leucine and valine arylamidases, lysozyme and naphthol-AS-BI-phosphohydrolase. Strain $332^{\mathrm{T}}$ exhibited weak proteolytic activity (hydrolysis of casein) but did not degrade starch.

PG in liquid medium supported growth of both strain $332^{\mathrm{T}}$ and D. tsuruhatensis DSM $17581^{\mathrm{T}}$. After 3 days, cell densities of strain $332^{\mathrm{T}}$ and D. tsuruhatensis DSM $17581^{\mathrm{T}}$ were 1.9- to 3.2-fold higher in the PG-enriched cultures than in cultures without PG. At day 5, the cell density had doubled again in the cultures of strain $332^{\mathrm{T}}$ enriched with PG, while no additional growth was found for $D$. tsuruhatensis DSM $17581^{\mathrm{T}}$ in the PG-enriched medium after day 3. On solid medium enriched with PG, 3-4 mm opaque zones were formed around the colonies, indicating some reaction with PG; no clear zones were observed. No DNase activity was observed for strain $332^{\mathrm{T}}, D$. tsuruhatensis DSM $17581^{\mathrm{T}}$ or D. acidovorans DSM $39^{\mathrm{T}}$. Differences between strain $332^{\mathrm{T}}, D$. tsuruhatensis DSM $17581^{\mathrm{T}}$ and $D$. acidovorans DSM $39^{\mathrm{T}}$ with respect to utilization of organic compounds and enzyme activities are given in Table 1.

The chitinase and lysozyme activities indicate that strain $332^{\mathrm{T}}$ has the capacity to break $\beta(1,4)$ glycosidic bonds in chitin and PG, and this may explain its success in utilizing bacterial cell-wall material from Gram-positive as well as Gram-negative bacteria, as observed during the initial screening on PG-enriched agar. The capacity to degrade chitin and PG has not previously been reported for the genus Delftia. The observed opaque, rather than clear, zones around the colonies on PG-enriched agar may indicate that PG was not completely degraded and assimilated by strain $332^{\mathrm{T}}$. The weak reaction on $N$ acetyl-D-glucosamine (Biolog and API kits) further suggests slow utilization of some PG components.

The dominant fatty acids in strain $332^{\mathrm{T}}$ were $\mathrm{C}_{16: 1} \omega 7 \mathrm{c} /$ iso$\mathrm{C}_{15: 0} 2-\mathrm{OH}\left(36.9 \%\right.$ of total fatty acid esters), $\mathrm{C}_{16: 0}$ (34.3\%), $\mathrm{C}_{18: 1} \omega 7 c(15.4 \%)$ and $\mathrm{C}_{17: 0}$ cyclo $(6.1 \%)$ (data not shown). Two fatty acids, $\mathrm{C}_{15: 1} \omega 6 c$ and $\mathrm{C}_{17: 1} \omega 8 c$, were not found in strain $332^{\mathrm{T}}$, but only in D. tsuruhatensis DSM $17581^{\mathrm{T}}$. The sum of the $\mathrm{C}_{17: 0}$ and $\mathrm{C}_{19: 0}$ cyclopropane fatty acids, which are produced mainly during the late growth phase, and their precursors, $\mathrm{C}_{17: 1} \omega 8 c+\mathrm{C}_{16: 1} \omega 5 c$ and $\mathrm{C}_{19: 0}$ cyclo $\omega 8 c+\mathrm{C}_{18: 1} \omega 7 c$, was higher in strain $332^{\mathrm{T}}(42.9$ and $16.1 \%$, respectively) than in $D$. tsuruhatensis DSM $17581^{\mathrm{T}}$ (41.0 and $14.8 \%$, respectively) (Table 1 ). $\mathrm{C}_{8: 0} 3-\mathrm{OH}$ and
$\mathrm{C}_{10: 0} 3-\mathrm{OH}$, which are characteristic fatty acids of the genus Delftia (Wen et al., 1999), were also found in strain $332^{\mathrm{T}}$, although $\mathrm{C}_{8: 0} 3-\mathrm{OH}$ occurred in only trace amounts $(0.2 \%$ of the total fatty acid esters). The DNA G+C content of strain $332^{\mathrm{T}}$ was $65.3 \mathrm{~mol} \%$.

BLAST (Johnson et al., 2008) and SEQMATCH (RDP 9 website; Cole et al., 2007) comparisons of 16S rRNA gene sequences both showed that strain $332^{\mathrm{T}}$ grouped within the family Comamonadaceae within the order Burkholderiales of the class Betaproteobacteria. Hence, all 55 published type-strain sequences within this family were retrieved from the RDP 9 database and used for initial phylogenetic analysis (Treebuilder; RDP 9) with Escherichia coli as the outgroup (data not shown). Based on taxonomic and sequencequality criteria, a subset of the 55 sequences was selected. These sequences were aligned (RDP 9) with subsequent manual inspection and minor corrections being performed in BioEdit (Hall, 1999) version 7.0.9.0, and CLUSTAL x 2.0 software (Larkin et al., 2007) was finally used for the calculation of pairwise nucleotide similarity values based on unambiguous nucleotides (Jukes-Cantor algorithm), for construction of phylogenetic trees by the neighbourjoining method and for validation of the tree topology by bootstrapping (1000 resamplings).

Phylogenetic analysis of the 16S rRNA gene sequences (Fig. 1) clearly showed that strain $332^{\mathrm{T}}$ belonged to the genus Delftia and further indicated that D. tsuruhatensis $\mathrm{T}^{\mathrm{T}}$ was the closest relative, with a nucleotide similarity of $99.9 \%$. This finding was substantiated in a subsequent phylogenetic analysis including 32 Delftia $16 \mathrm{~S}$ rRNA gene sequences present within the RDP 9 database (not shown). Hence, all Delftia sequences could be divided into two phylogenetic clusters, supported by a bootstrap value of $57 \%$, with $D$. acidovorans sequences in one cluster and D. tsuruhatensis sequences and strain $332^{\mathrm{T}}$ in the other cluster.

DNA-DNA hybridization experiments performed at the DSMZ using standard protocols confirmed the close taxonomic relationship between strain $332^{\mathrm{T}}$ and $D$. tsuruhatensis DSM $17581^{\mathrm{T}}$ and, to a lesser extent, also with D. acidovorans DSM $39^{\mathrm{T}}$ (Table 1). However, the DNA-DNA relatedness values fell below the $70 \%$ threshold value for the delineation of novel species (Wayne et al., 1987). Distinct phenotypic characteristics were observed for strain $332^{\mathrm{T}}$ (capacity to utilize D-mannitol, D-malic acid, D-galactonic acid lactone and D-gluconic acid, as well as chitinase activity and a significantly higher growth with PG in liquid medium; Table 1), and therefore we propose that the PG-degrading strain that has been isolated from lake water represents a novel species within the genus Delftia, for which the name Delftia lacustris sp. nov. is proposed.

\section{Emended description of Delftia tsuruhatensis Shigematsu et al. 2003}

In the original description by Shigematsu et al. (2003), information on degradation of PG was not included. Tests 
Table 1. Differential characteristics of strain $332^{\top}$ and the type strains of Delftia species

Strains: 1 , Delftia lacustris sp. nov. $332^{\mathrm{T}} ; 2$, D. tsuruhatensis DSM $17581^{\mathrm{T}} ; 3$, D. acidovorans DSM $39^{\mathrm{T}}$. + , Positive; w, weak; -, negative; ND, not reported/not determined. Data were obtained in this study unless indicated otherwise.

\begin{tabular}{|c|c|c|c|}
\hline Characteristic & 1 & 2 & 3 \\
\hline \multicolumn{4}{|l|}{ Use of carbon sources for growth } \\
\hline D-Mannitol & + & - & $+^{*}$ \\
\hline D-Malic acid & + & - & $+^{*}$ \\
\hline D-Galactonic acid lactone & $\mathrm{W}$ & - & ND \\
\hline D-Gluconic acid & $\mathrm{w}$ & - & $+^{*}$ \\
\hline$\gamma$-Hydroxybutyric acid & + & + & - \\
\hline L-Serine & - & - & $\mathrm{w}^{\dagger}$ \\
\hline \multicolumn{4}{|l|}{ Enzyme activities } \\
\hline Chitinase & + & - & ND \\
\hline Lysozyme & + & $+\ddagger$ & ND \\
\hline Proteolytic (casein) & $\mathrm{w}$ & $\mathrm{W}$ & $-{ }^{*}$ \\
\hline Degradation of PG in liquid culture and agar & + & + & ND \\
\hline Major 3-OH fatty acids & $10: 0,8: 0$ & $10: 0$ & $10: 0,8: 0^{*}$ \\
\hline \multicolumn{4}{|l|}{ Cellular lipids (\%) } \\
\hline $\mathrm{C}_{15: 0}$ & 0.69 & 4.22 & ND \\
\hline $\mathrm{C}_{17: 0}$ & 0.31 & 1.79 & ND \\
\hline $\mathrm{C}_{17: 1} \omega 8 c+\mathrm{C}_{16: 1} \omega 5 c$ & 42.9 & 41.0 & ND \\
\hline $\mathrm{C}_{19: 0}$ cyclo $\omega 8 c+\mathrm{C}_{18: 1} \omega 7 c$ & 16.1 & 14.8 & ND \\
\hline DNA G + C content $(\mathrm{mol} \%)$ & 65.3 & 66.211 & $67^{*}$ \\
\hline DNA-DNA relatedness to strain $332^{\mathrm{T}}$ & ND & $66.2 \pm 0.6$ & $36.0 \pm 4.2$ \\
\hline
\end{tabular}

${ }^{\star}$ Data from Wen et al. (1999).

$\dagger$ Wen et al. (1999) did not observe growth on L-serine.

$\ddagger$ Lysozyme activity was about $25 \%$ higher for D. tsuruhatensis DSM $17581^{\mathrm{T}}$ than for strain $332^{\mathrm{T}}$.

$\S$ Liquefaction of gelatin was negative.

IIData from Shigematsu et al. (2003).

demonstrate that $D$. tsuruhatensis DSM $17581^{\mathrm{T}}$ is capable of degrading PG in both liquid and solid media, and that it possesses extracellular lysozyme activity (Table 1). In

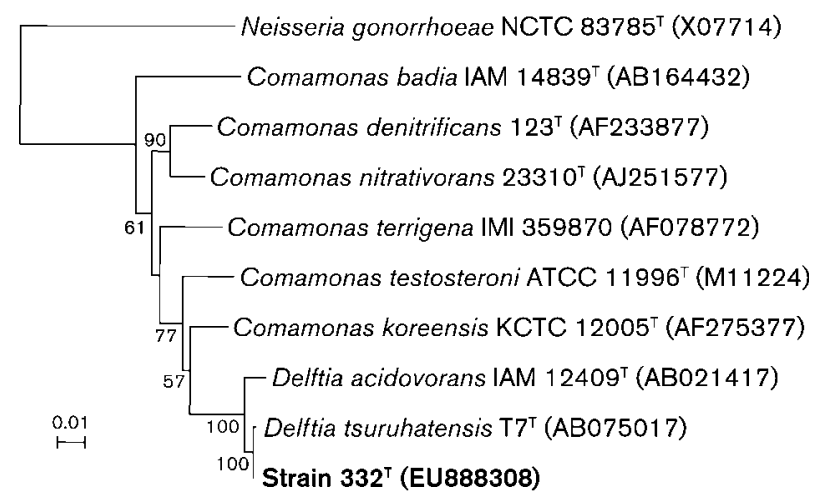

Fig. 1. Neighbour-joining phylogenetic tree based on 16S rRNA gene sequences from strain $332^{\top}$ and related type strains. Neisseria gonorrhoeae NCTC $8375^{\top}$ was used as the outgroup. Bootstrap values ( $\geqslant 50 \%$ ) based on 1000 resamplings are shown at branch nodes. Bar, 0.01 substitutions per site. contrast to strain $332^{\mathrm{T}}$, no chitinase activity is found in D. tsuruhatensis DSM $17581^{\mathrm{T}}$.

\section{Description of Delftia lacustris sp. nov.}

Delftia lacustris [la.cus'tris. N.L. fem. adj. lacustris (L. n. lacus a lake) growing by lakes or ponds].

Gram-negative-staining, motile rods $(2.3 \pm 0.7 \times 0.7 \pm$ $0.1 \mu \mathrm{m})$. Growth occurs at $3-37^{\circ} \mathrm{C}$; optimum growth at $25^{\circ} \mathrm{C}$. Growth occurs at $\mathrm{pH} 5-10$; optimum growth at $\mathrm{pH}$ 6-7. Growth occurs at salinities of $0-6 \mathrm{~g} \mathrm{NaCl} \mathrm{l}^{-1}$; optimum growth at $1 \mathrm{~g} \mathrm{l}^{-1}$. Doubling time is $1.7 \mathrm{~h}$ at $20{ }^{\circ} \mathrm{C}$ with full-strength TSB. Non-fermentative. Positive for acid and alkaline phosphatases, chitinase, esterase (C4), esterase lipase (C8), $\alpha$ - and $\beta$-glucosidases, leucine and valine arylamidases, lysozyme and naphthol-AS-BI-phosphohydrolase. Denitrification ability is not observed, but nitrate reduction is observed. The following compounds can be utilized as energy and carbon sources: phenylacetic acid, L-asparagine, adipic acid, 4-hydroxybenzoic acid, $\alpha$ ketobutyric acid, caproic acid, citrate, gluconic acid, 2- and 5-ketogluconate, itaconic acid, D-malic acid, malonic acid, L-phenylalanine, L-threonine, L-arabinose, $\mathrm{N}$-acetyl-D-glu- 
cosamine, D-glucose, D-mannose, glycogen, D-mannitol, gelatin, peptidoglycan, pyruvic acid methyl ester and Tweens 40 and 80. The following compounds cannot be utilized: D-glucose, cellobiose, aesculin, galactopyranoside, glucose 1-phosphate, glycogen, maltose, $\alpha$-cyclodextrin, methyl $\beta$-D-glucoside, D-xylose, i-erythritol, D-galactonic acid $\gamma$-lactone, L-arginine, D-galacturonic acid, 2-hydroxybenzoic acid, L-serine, D-glucosaminic acid, glycyl Lglutamic acid, phenylethylamine, $\alpha$-lactose, DL- $\alpha$-glycerol phosphate, putrescine and tryptophan. The dominant cellular fatty acids are $\mathrm{C}_{16: 1} \omega 7 c /$ iso- $\mathrm{C}_{15: 0} 2-\mathrm{OH}, \mathrm{C}_{16: 0}$, $\mathrm{C}_{18: 1} \omega 7 c$ and $\mathrm{C}_{17: 0}$ cyclo; $\mathrm{C}_{10: 0} 3-\mathrm{OH}, \mathrm{C}_{12: 0}, \mathrm{C}_{14: 0}, \mathrm{C}_{15: 0}$ and $\mathrm{C}_{8: 0} 3-\mathrm{OH}$ are found in smaller amounts. The DNA $\mathrm{G}+\mathrm{C}$ content of the type strain is $65.3 \mathrm{~mol} \%$.

The type strain is $332^{\mathrm{T}}\left(=\mathrm{DSM} 21246^{\mathrm{T}}=\mathrm{LMG} 24775^{\mathrm{T}}\right)$, isolated from mesotrophic lake water.

\section{Acknowledgements}

We thank Ann-Siri Berg Hentze, Susanne Iversen, Dorte Rasmussen and May-Britt Prahm for laboratory assistance during isolation and characterization of the strain. We also acknowledge valuable comments from three reviewers and Professor Rainer Kroppenstedt at the DSMZ regarding the content of fatty acids in strain $332^{\mathrm{T}}$. The project was supported by The Danish Natural Science Research Council, grant no. 21-01-0537, to N. O. G. J and O. N. K. K. B. acknowledges support from the Center for Environmental and Agricultural Microbiology (CREAM), funded by the Villum Kann Rasmussen Foundation.

\section{References}

Benner, R. \& Kaiser, K. (2003). Abundance of amino sugars and peptidoglycan in marine particulate and dissolved organic matter. Limnol Oceanogr 48, 118-128.

Brandt, K. K., Patel, B. K. C. \& Ingvorsen, K. (1999). Desulfocella halophila gen. nov., sp. nov., a halophilic fatty acid-oxidizing sulfatereducing bacterium isolated from sediments of the Great Salt Lake. Int J Syst Bacteriol 49, 193-200.

Brandt, K. K., Petersen, A., Holm, P. E. \& Nybroe, O. (2006). Decreased abundance and diversity of culturable Pseudomonas spp. populations with increasing copper exposure in the sugar beet rhizosphere. FEMS Microbiol Ecol 56, 281-291.

Cody, R. M. (1989). Distribution of chitinase and chitobiase in Bacillus. Curr Microbiol 19, 201-205.

Cole, J. R., Chai, B., Farris, R. J., Wang, Q., Kulam-Syed-Mohideen, A. S., McGarrell, D. M., Bandela, A. M., Cardenas, E., Garrity, G. M. \& Tiedje, J. M. (2007). The Ribosomal Database Project (RDP-II): introducing myRDP space and quality controlled public data. Nucleic Acids Res 35, D169-D172.

De Ley, J., Cattoir, H. \& Reynaert, A. (1970). Quantitative measurement of DNA hybridization from renaturation rates. Eur $J$ Biochem 12, 133-142.

Eisenstadt, E., Carlton, B. C. \& Brown, B. J. (1994). Gene mutation. In Methods for General and Molecular Bacteriology, pp. 297-316.
Edited by P. Gerhardt, R. G. E. Murray, W. A. Wood \& N. R. Krieg. Washington, DC: American Society for Microbiology.

Frette, L., Johnsen, K., Jørgensen, N. O. G., Nybroe, O. \& Kroer, N. (2004). Functional characteristics of culturable bacterioplankton from marine and estuarine environments. Int Microbiol 7, 219-227.

Hall, T. A. (1999). BioEdit: a user-friendly biological sequence alignment editor and analysis program for Windows 95/98/NT. Nucleic Acids Symp Ser 41, 95-98.

Hugh, R. \& Leifson, E. (1953). The taxonomic significance of fermentative versus oxidative metabolism of carbohydrates by various gram negative bacteria. J Bacteriol 66, 24-26.

Jeffries, C. D., Holtman, D. F. \& Guse, D. G. (1957). Rapid method for determining the activity of microorganisms on nucleic acids. J Bacteriol 73, 590-591.

Johnson, M., Zaretskaya, I., Raytselis, Y., Merezhuk, Y., McGinnis, S. \& Madden, T. L. (2008). NCBI BLAST: a better web interface. Nucleic Acids Res 36, W5-W9.

Larkin, M. A., Blackshields, G., Brown, N. P., Chenna, R., McGettigan, P. A., McWilliam, H., Valentin, F., Wallace, I. M., Wilm, A. \& other authors (2007). CLUSTAL W and CLUSTAL_X version 2.0. Bioinformatics 23, 2947-2948.

Nagata, T., Meon, B. \& Kirchman, D. L. (2003). Microbial degradation of peptidoglycan in seawater. Limnol Oceanogr 48, 745-754.

O'Brien, M. \& Colwell, R. R. (1987). A rapid test for chitinase activity that uses 4-methylumbelliferyl- $N$-acetyl-beta-D-glucosaminide. Appl Environ Microbiol 53, 1718-1720.

Park, J. T. \& Uehara, T. (2008). How bacteria consume their own exoskeletons (turnover and recycling of cell wall peptidoglycan). Microbiol Mol Biol Rev 72, 211-227.

Pelz, O., Cifuentes, L. A., Hammer, B. T., Kelley, C. A. \& Coffin, R. B. (1998). Tracing the assimilation of organic compounds using $\delta^{13} \mathrm{C}$ analysis of unique amino acids in the bacterial peptidoglycan cell wall. FEMS Microbiol Ecol 25, 229-240.

Shigematsu, T., Yumihara, K., Ueda, Y., Numaguchi, M., Morimura, S. \& Kida, K. (2003). Delftia tsuruhatensis sp nov., a terephthalateassimilating bacterium isolated from activated sludge. Int J Syst Evol Microbiol 53, 1479-1483.

Wang, S. L. \& Chang, W. T. (1997). Purification and characterization of two bifunctional chitinases/lysozymes extracellularly produced by Pseudomonas aeruginosa K-187 in a shrimp and crab shell powder medium. Appl Environ Microbiol 63, 380-386.

Watson, L. P., McKee, A. E. \& Merrell, B. R. (1980). Preparation of microbiological specimens for scanning electron microscopy. Scan Electron Microsc 2, 45-56.

Wayne, L. G., Brenner, D. J., Colwell, R. R., Grimont, P. A. D., Kandler, O., Krichevsky, M. I., Moore, L. H., Moore, W. E. C., Murray, R. G. E. \& other authors (1987). International Committee on Systematic Bacteriology. Report of the ad hoc committee on reconciliation of approaches to bacterial systematics. Int J Syst Bacteriol 37, 463464.

Wen, A., Fegan, M., Hayward, C., Chakraborty, S. \& Sly, L. I. (1999). Phylogenetic relationships among members of the Comamonadaceae, and description of Delftia acidovorans (den Dooren de Jong 1926 and Tamaoka et al. 1987) gen. nov., comb. nov. Int J Syst Bacteriol 49, 567-576. 